\title{
Long-term clinical complications associated with the use of polymethyl methacrylate in spinal stabilization of dogs and cats: case series
}

\section{Complicações clínicas de longo prazo relacionadas ao uso de pino ou parafuso/polimetilmetacrilato na estabilização espinhal de cães e gatos: série de casos}

\author{
Gabriel Antonio Covino Diamante ${ }^{1^{*}}$; Paulo Vinicius Tertuliano Marinho²; \\ Isis dos Santos Dal-Bó ${ }^{1}$; Thales Bregadioli ${ }^{1}$; Fernanda Paes ${ }^{1}$; \\ Renato Otaviano do Rego'; Bianca Fiuza Monteiro ${ }^{3}$; Viviane Sanchez Galeazzi ${ }^{4}$; \\ Aline Schafrum Macedo ${ }^{1}$; Cássio Ricardo Auada Ferrigno ${ }^{5}$
}

\section{Highlights:}

Even the "gold standard" to treat vertebral or fracture luxations has complication. All patients treated surgically must be monitored for long periods after discharge. Implant removal is important to treat infection and improve the treatment outcome.

\begin{abstract}
Vertebral and spinal cord trauma are common conditions in small animal practice and often result in vertebral fractures/luxation (VFL) with concomitant spinal cord laceration, concussion, compression, or ischemia. These lesions have several clinical presentations that may vary from moderate to severe pain and partial to total loss of motor, sensory, and visceral functions, which may result in death or euthanasia. Our purpose is to describe five cases (four dogs and one cat) of complications secondary to the use of bone cement for vertebral stabilization. The patients, between five months and four years of age and weighing between 1.4 and $12.2 \mathrm{~kg}$, were referred to the Small Animal Orthopedics and Traumatology Service of the Veterinary Hospital of the College of Veterinary Medicine and Animal Science of the University of São Paulo. They had a history of post-operatory polymethyl methacrylate (PMMA) reactions (such as drainage or cement exposure due to infection or implant failure) in periods from 9 to 18 months after undergoing spinal osteosynthesis. Surgical implant removal occurred in $80 \%$ of the patients (4/5). Complete remission was not observed in the patient with residual implants. The association of pins/screws and PMMA is a versatile osteosynthesis technique and is applicable in all spinal regions. However, delayed complications can occur, which could require additional surgical procedures. Despite the small number of cases included in this study, one can infer that complications related to the use of bone cement in spinal surgery can occur in the long term and should be highlighted during the implant choosing process for vertebral osteosynthesis in small animals.
\end{abstract}

\footnotetext{
1 Prof. Dr., Curso de Medicina Veterinária, Instituto Federal do Sul de Minas, IFSULDEMINAS, Muzambinho, MG, Brasil. E-mail: paulo.veter@gmail.com

3 Discente, Curso de Mestrado do Programa de Pós-Graduação em Clínica Cirúrgica Veterinária, USP, São Paulo, SP, Brasil. E-mail: bianca.fiuza@hotmail.com

4 Médica Veterinária do Serviço de Ortopedia, USP, São Paulo, SP, Brasil. E-mail: vsgaleazzi@usp.br

5 Prof. Dr., Curso de Mestrado e Doutorado do Programa de Pós-Graduação em Clínica Cirúrgica Veterinária, USP, São Paulo, SP, Brasil.E-mail: cassioaf@usp.br

* Author for correspndence
} 
Key words: Bone cement. Postoperative complications. Adverse effects. Spinal column.

\section{Resumo}

O trauma vertebromedular é uma afecção comum na rotina clínica de pequenos animais e resulta, muitas vezes, em fraturas e luxações vertebrais (FLV) associadas à laceração, concussão, compressão ou isquemia da medula espinhal. Essas lesões apresentam sinais clínicos que variam de dor moderada a grave, acompanhada por perda parcial ou total das funções motoras, sensoriais e viscerais, podendo resultar no óbito ou na indicação de eutanásia. O objetivo deste trabalho é descrever cinco casos de complicações inerentes o uso de cimento ósseo para estabilização vertebral em quatro cães e um gato. Os pacientes possuíam idades variando entre cinco meses a quatro anos, peso entre 1,4 e 12,2kg e foram atendidos no Serviço de Ortopedia e Traumatologia do Hospital Veterinário da Faculdade de Medicina Veterinária e Zootecnia da Universidade de São Paulo, com histórico de reações cutâneas ao polimetilmetacrilato (PMMA), como tratos drenantes ou exposição do cimento decorrente de infecção ou soltura precoce do implante, em períodos que variaram de nove à 18 meses após serem submetidos a osteossíntese da coluna vertebral. Foi realizada a remoção cirúrgica desses implantes em quatro pacientes e mantida a estabilização prévia em um caso. Houve resolução total do quadro de infecção nos pacientes em que se removeu o PMMA associada ao tratamento clínico, e remissão parcial no paciente em que o implante não pode ser removido. A utilização do cimento ósseo associado a parafusos ou pinos é uma técnica versátil e aplicável em todas as regiões da coluna vertebral, no entanto complicações tardias são possíveis, sendo necessário muitas vezes procedimentos cirúrgicos adicionais para a resolução do problema. Apesar da pequena quantidade de casos relatados, foi possível observar que complicações relacionadas ao uso do cimento ósseo na coluna vertebral podem ocorrer no médio ao longo prazo e devem ser consideradas no processo de escolha dos implantes para osteossíntese vertebral em pequenos animais.

Palavras-chave: Cimento ósseo. Complicações pós-operatórias. Efeitos adversos. Coluna vertebral.

\section{Introduction}

Vertebral and spinal cord trauma are common in small animal practice and often result in vertebral fractures and luxation (VFL) associated with laceration, concussion, or ischemia of the spinal cord. These injuries present with moderate to severe pain, accompanied by partial or total loss of motor, sensory, and visceral functions, which may result in death or euthanasia (DiFazio, Fletcher, 2013; Jeffery, 2010). A high energy trauma is necessary to rupture the spine structure. The most common cause in dogs and cats are automobile accidents, which represent $63.2 \%$ of cases, followed by fall from significant heights (Bruce, Brisson, \& Gyselinck, 2008; Hettlich, 2017; Vallefuoco et al., 2014).

The main objectives during the treatment of VFL are to provide an environment in which the injured neural tissue may recover and to allow proper bone healing to avoid additional injury to the spinal cord due to vertebral instability. VFL that compromise two or three vertebral compartments are considered mechanically and clinically unstable. In these cases, surgical treatment is indicated with internal fixation using implants that provide the necessary rigidity (DiFazio, Fletcher, 2013; Hettlich, 2017; Jeffery, 2010; Shores, Braund, \& Brawnerr, 1990).

Various implants have been described and used for internal stabilization of VFLs. Among them are various models of plates and screws, such as the limited contact dynamic compression plate (LCDCP), the locking plate (LCP), and the "String of Pearls" plate (SOP). Pins with or without cerclage wires, titanium pedicular screws, and pins or 
screws and polymethyl methacrylate (PMMA) bone cement are used as well. The latter method is considered the "gold standard" for the fixation of VFLs in dogs and cats (Bruce et al., 2008; Jeffery, 2010; Hettlich, 2017). However, complications related to the use of PMMA in the internal fixation of VFLs have been reported. These include thermal necrosis, infection, breakage or loosening of the PMMA, seroma caused by dead space, and muscular atrophy adjacent to the bone cement, resulting in deformities of the vertebral column (Hettlich, 2017; Vallefuoco et al., 2014).

The present study, involving five animals, reports the medium and long-term complications inherent to the use of bone cement with pins or screws for stabilization of the vertebral column, such as open wounds with exposure of the PMMA with or without infection, and describes the treatment and prognosis for each case. The authors believe that the experiences discussed in the present study will provide relevant information for surgical planning in cases of VFL and treatment of the complications that may occur.

\section{Case series}

All cases reported here, four dogs and a cat of various ages (between five months and four years), presented to the Small Animal Orthopedics and Traumatology Service of the Veterinary Hospital of the College of Veterinary Medicine and Animal Sciences of the University of São Paulo with post-surgical cutaneous reactions to PMMA. In four cases (cases 2, 3, 4, 5), the reconstructive spinal surgery had been performed by Master's and Doctorate post-graduate students, under the supervision of a surgery professor, and in one case (case 1), the surgery had been performed outside the university and was referred only for the treatment of the complication (Table 1).

\section{Table 1}

Summary of the cases reported displaying species, age, breed, gender, initial cause of injury, time from surgery to development of clinical signs, as well as culture results from the analyzed samples

\begin{tabular}{cccccccc}
\hline & Species & Age & Breed & Gender & $\begin{array}{c}\text { Initial Cause of } \\
\text { Injury }\end{array}$ & Time & Culture Results \\
\hline Case 1 & CAN & $2 \mathrm{Y}$ & mixed & M & Hit by car & 18 Months & ----- \\
\hline Case 2 & CAN & $1.5 \mathrm{Y}$ & mixed & F & Hit by car & 11 Months & coagulase + ve Staphylococcus \\
\hline Case 3 & CAN & $4 \mathrm{Y}$ & mixed & M & Hit by car & 18 Months & Escherichia Coli \\
\hline Case 4 & FEL & $5 \mathrm{M}$ & mixed & F & Attacked by Dog & 9 Months & $\begin{array}{c}\text { beta-lactamase-producing S. } \\
\text { S. aureus (MRSA) }\end{array}$ \\
\hline Case 5 & CAN & $8 \mathrm{M}$ & Pug & F & Hemivertebra & 10 Months & ----- \\
\hline
\end{tabular}

Case 1: dog, 2 years of age, mixed breed, weighing $12.2 \mathrm{~kg}$, presented with exposure of the bone cement at the thoracolumbar spine, 1.5 years after the initial surgery. The patient was surgically treated with Steinmann pins and PMMA for a fracture/subluxation of the T12-T13 segment from an automobile accident. The physical examination revealed a cutaneous discontinuity, with part exposure of the bone cement. On palpation, mobility or loosening of the implant was noted (Figure 1A).

On the radiographs, two of the six pins inserted into the bodies of T12-T13 were observed to be broken and still adhered to the PMMA (Figure 1B). A decision was made for surgical removal of the implants, which were sent for bacterial culture and 
antibiogram. The surgical wound healed in ten days There was no bacterial growth from the fragments without complications and no seroma was formed. sent for analysis.

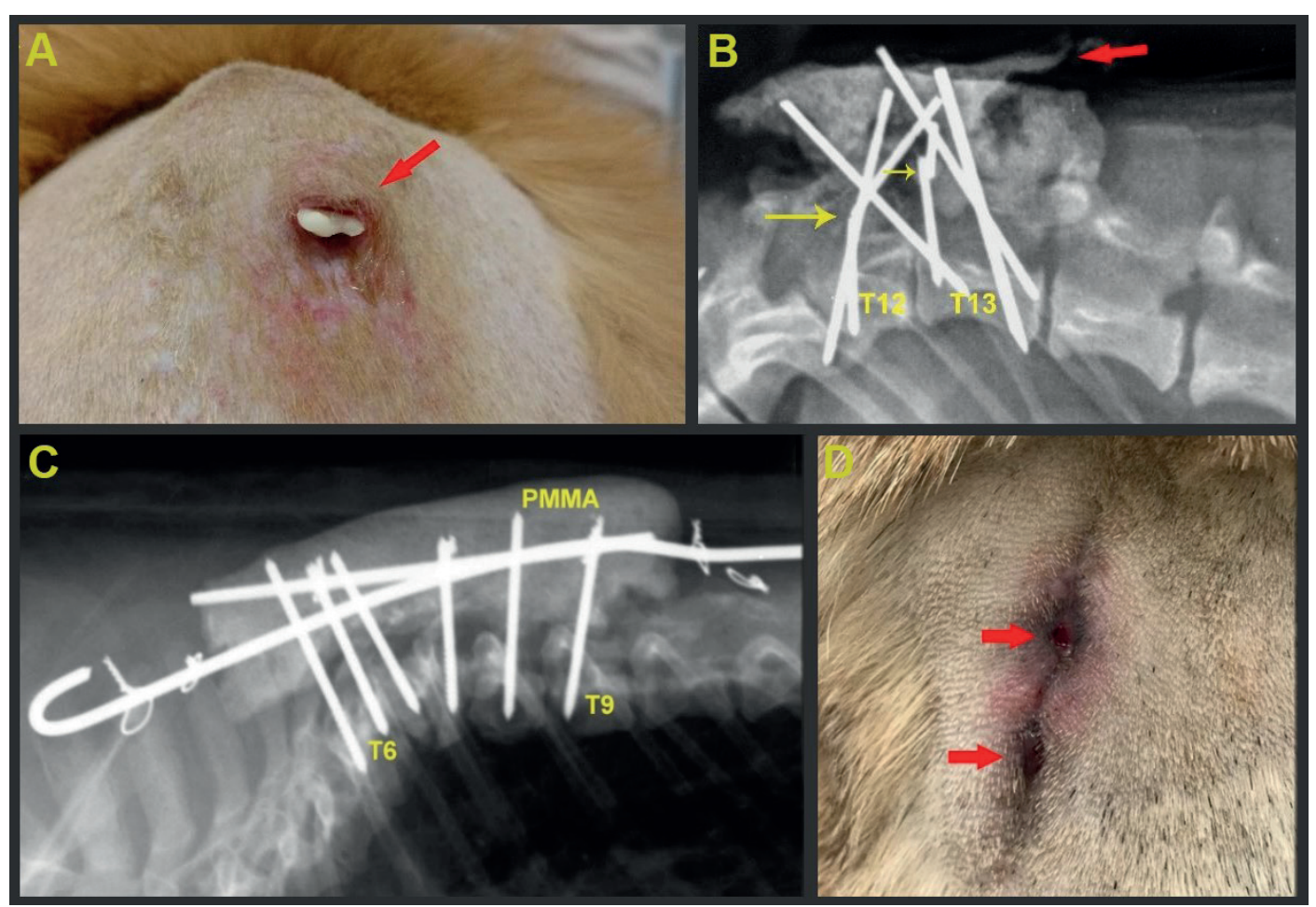

Figure 1. Case 1: dog, male, two years of age, mixed breed, weighing $12.2 \mathrm{Kg}$, presented due to exposure of the bone cement at the thoracolumbar spine 1.5 years after initial surgery.

A: wound showing exposure of the PMMA to the environment (red arrow); B: Radiograph of the thoracolumbar spine showing two broken pins (yellow arrows) and the exposed portion of the PMMA (red arrow). Case 5: dog, female, eight months of age, Pug breed, weighing $5.4 \mathrm{Kg}$ with hemivertebra at T7; C: Immediate post-operatory radiograph; D: Wound with open orifices during conservative treatment.

Case 2: dog, female, 1.5 years of age, mixed breed, weighing $10 \mathrm{~kg}$, presented with sustained trauma after five days of an automobile accident. Neurologic examination showed paraplegia with superficial pain; there were no other significant changes on general physical examination. After external immobilization of the entire vertebral column, the patient was referred for radiographs of the thoracolumbar spine, which revealed a fracture at L3 and subluxation between T11-T12. Fracture of the body of L3 was reduced and stabilized with a titanium 2-mm ${ }^{1}$ locking plate. The thoracic subluxation was stabilized with cortical screws and PMMA. Twelve days after the procedure, the surgical wound had healed uneventfully, and the patient was able to ambulate on its own, however, proprioceptive ataxia was present in the pelvic limbs (PLs).

After 11 months, the patient returned with a moist wound at the site of the surgical incision, with approximately 1 month of duration. A draining tract with serosanguinous discharge and partial exposure

\footnotetext{
1 Tóride $^{\circledR}$. www.torideimplantes.com.br
} 
of the bone cement were noted. Radiographs of the thoracolumbar spine showed partial loosening of the screws enveloped by the PMMA; there were no radiographic signs suggesting instability around the locking plate. The screws and PMMA were surgically removed and sent for culture and antibiogram. Postoperative antibiotic therapy of cefalexin $(30 \mathrm{mg} /$ $\mathrm{kg}$ ) BID for 10 days, was prescribed. Post-operative oral analgesia was prescribed, carprofen $(2.2 \mathrm{mg} /$ $\mathrm{kg}$ ) BID for 5 days and tramadol hydrochloride (3 $\mathrm{mg} / \mathrm{kg}$ ) TID for 5 days.

On the tenth day after surgery, there was partial wound dehiscence (approximately $2 \mathrm{~cm}$ ) at the suture site, without any discharge. The result of the bacterial culture and antibiogram of the implants showed growth of coagulase-positive Staphylococcus that was only sensitive to doxycycline. Oral doxycycline (10 mg/kg) SID was administered for 10 days. The patient was re-evaluated and discharged after complete wound healing.

Case 3: dog, male, 4 years of age, mixed breed, weighing $11 \mathrm{~kg}$, presented with difficulty in walking with PLs four days after trauma from a car accident. On gait evaluation, ataxia and paresis of the pelvic limbs were identified, worse in the left PL. On orthopedic examination, there was pain on epaxial palpation of the lumbar spine. Radiographs of the thoracolumbar spine showed VFL between the L5 and L6. The VFL was stabilized using PMMA and cortical screws. Ten days after surgery, the sutures were removed and the wound had healed without complications.

The owner brought the patient back one year and six months after the first discharge, concerned about a lump over the lumbar spine. A firm mass was observed over the surgical site. There was a draining tract of approximately $1 \mathrm{~cm}$ in diameter with an odorless serosanguineous discharge. Neurologic exam showed decreased tone and proprioception in pelvic limbs (PLs), but without significant changes to the gait.
Radiographically, no signs of loosening or instability of the implants was noted. Oral administration of antibiotic therapy with cefalexin $(30 \mathrm{mg} / \mathrm{kg}$ ) BID for 10 days and analgesia with carprofen $(2.2 \mathrm{mg} / \mathrm{kg})$ BID for 5 days and tramadol hydrochloride $(2 \mathrm{mg} / \mathrm{kg}$ ) BID for 5 days was considered. Following surgical removal of the implants, the culture and antibiogram revealed Escherichia coli and sensitivity to cefalexin. After 10 days of the medical therapy, sutures were removed and wound healing was analyzed. The patient was then discharged.

Case 4: cat, female, five months of age, mixed breed, weighing $1.4 \mathrm{~kg}$, visited due to trauma from a large-breed dog bite 15 hours earlier. Two puncture wounds were observed on the dorsal region of the lumbar spine with an adjacent hematoma. Neurologic exam findings were paraplegia, absent deep pain, decreased muscle tone, and reduced bilateral patellar and flexor reflexes, directing to a possible lesion at the lumbosacral intumescence. After analgesia and stabilization of the patient's condition, radiographs were obtained, which showed fracture of the caudal epiphyseal disc of L6 as well as subluxation of L6 in relation to L7.

The patient was prescribed amoxicillin and clavulanic acid $(20 \mathrm{mg} / \mathrm{kg})$ BID for 10 days, metronidazole $(25 \mathrm{mg} / \mathrm{kg})$ BID for 5 days, and tramadol hydrochloride (4 $\mathrm{mg} / \mathrm{kg})$ TID for seven days, all administered orally. Surgery was performed two days after initial presentation, and vertebral osteosynthesis was achieved by inserting six $1.5 \mathrm{~mm}$ diameter cortical screws into the vertebral bodies of L5 to L7 and two 2- $\mathrm{mm}^{2}$ cortical screws into the wings of the ilium with PMMA. After completion of the course of medications, the patient was discharged but returned two weeks later with increased sensitivity and a sinus opening at the surgical site. A 15-day empirical antibiotic course of amoxicillin and clavulanic acid, similar to the previously described dose, resulted in remission of the clinical signs.

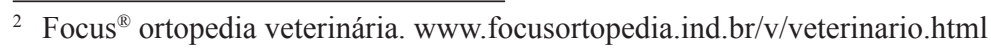


Nine months after surgery, the patient again presented to the service, this time for a wound at the lumbar spine, with exposure of the PMMA. The radiographs did not reveal signs of loosening or instability of the implants. Surgical removal of the implants was performed along with culture and antibiogram. Five days after surgery, the patient returned with severe pain and edema at the surgery site. Radiographs showed misalignment of L6 and L7 vertebrae and vertebral instability. Another surgery was planned after three days, with two 2-mm ${ }^{1}$ titanium-locking plates placed at L6L7, one with five screws on the left side and one with four screws on the right. Culture was positive for beta-lactamase-producing Staphylococcus and methicillin-resistant Staphylococcus aureus (MRSA), both sensitive to doxycycline, which was prescribed for 60 days at a dose of $5 \mathrm{mg} / \mathrm{kg}$, orally, BID, with positive resolution of the case.

Case 5: A dog, female, eight months of age, Pug breed, weighing $5.4 \mathrm{~kg}$, presented with onemonth history of acute paraplegia after a bath. Thoracolumbar syndrome was observed, with deep pain present. Radiographically, deformity of the vertebral segment was seen between T6 and T8, with hemivertebra at T7. After computed tomography was performed for surgical planning, the patient underwent surgery for stabilization of the thoracic spine using 1.5- $\mathrm{mm}^{3}$ Schanz pins from T6 to T9 with PMMA and segmental fixation from $\mathrm{T} 2$ to T12 with 2-mm pin and cerclage (Figure 1C). The patient showed significant neurologic improvement and continued to wear an external immobilization vest for three months. Two weeks after removal of the vest, a draining tract with purulent discharge appeared at the surgical site. The wound was cleaned, followed by antibiotic therapy of cefalexin $30 \mathrm{mg} / \mathrm{kg}$ BID for 30 days, orally, which resulted in complete healing.

Ten months after the surgery, the patient returned due to mild limping in the left PL and with a wound dorsal to the PMMA at the thoracic region (Figure 1D). Hair was clipped from the area and cleaned with chlorhexidine and $\mathrm{NaCl} 0.9 \%$ (normal saline). Due to the risk for vertebral destabilization after removal of the implants, the owner decided against the surgery. The wound recurred six months later, but the owners did not consent to surgery.

\section{Discussion}

Stabilization of VFLs using PMMA bone cement and pins or screws can be versatile and effective; several authors reported good results and success rates, and many surgeons use this combination (Bruce et al., 2008; Difazio \& Fletcher, 2013). However, complications related to infection of the surgery site, such as seroma, hypersensitivity to the cement, early loosening of the implants, or even development of an open wound may occur later, even after discharge and recovery of the patient, and may evolve to severe consequences. It is recommended that in the pre-operative planning period, such possibilities are explained to the owners and considered as important factors when choosing surgical implants.

Reaction to implants, whether metallic or nonmetallic, may be immunological in origin, related to type IV hypersensitivity mediated by T lymphocytes, which has a delayed characteristic. This type of reaction is generally caused by the release of implant particles due to corrosion, abrasion, or dissolution. PMMA is possibly the most reactive non-metallic implant in human patients, because of some of its components, such as N-dimethyl-para-toluidine, an accelerator used in some types of bone cement, and other additives such as benzoyl peroxide and hydroquinone (Roberts, Haines, \& Uhl, 2017).

Patients with hypersensitivity to an implant will generally develop prolonged eczematous dermatitis over the surgery site and may have pain and swelling during the post-operative period, characteristics

\footnotetext{
3 Synthes ${ }^{\circledR}$. https://catalog.synthes.com/
} 
which were not observed in the aforementioned cases. However, hypersensitivity reactions to internal fixation devices are significantly less intense than in arthroplasties due to absence of micro-movements between the implant and the bone, particularly after bone healing (Roberts et al., 2017). Nonetheless, the vertebral column has physiologic motion, and its fixation, especially without vertebral fusion, probably exposes the implants to a greater and longer-lasting cyclical load than osteosynthesis of long bones, which could predispose the implant to the release of particles into the bloodstream.

The infection rate among the patients in this series was $60 \%$. It is difficult to infer whether the infection occurred before or after the exposure of PMMA. A study by Petty, Spanier, Shuster and Silverthorne (1985)instilled a suspension of bacteria, and then inserted one of the implants. The implants--stainless-steel and cobaltchromium alloys, high-density polyethylene, prepolymerized polymethylmethacrylate, and polymethylmethacrylate polymerized in vivo--were compared with no implant (control, consisting of inoculation of Escherichia coli and Staphylococcus epidermitis into the femur of 187 dogs, showed that in vivo polymerization of paste form of PMMA, as done for vertebral stabilizations in dogs and cats, had significantly higher infection rates when compared to steel, cobalt-chrome alloy, or polyethylene implants, even in lower bacterial concentrations.

Moreover, the paste phase of PMMA may overflow and cause local complications such as compression of the spinal cord or nerve roots, resulting in myelopathies or radiculopathies that are often untreatable by conservative means and require decompressive surgery $(\mathrm{Wu}, \mathrm{Lin}$, Yang, Chen, \& Shih, 2007)

Vallefuoco et al. (2014) reported long-term complications (12 months) when evaluating eight cats that underwent osteosynthesis with cortical screws and PMMA; only one patient had breakage of PMMA two weeks after surgery and needed a new intervention. Bruce et al. (2008), in a retrospective study, reported the need for surgical intervention in 3 of the 13 cases treated with pins/PMMA, with a mean time of 49 days from the surgery; however, those authors reported that the higher complication rate owed to the lack of long-term follow-up in some patients. In contrast, in our cases, the mean time between surgery and development of a wound exposing the bone cement was 13.2 months (9-18). Two of the cases presented after 18 months and would not have been detected in a shorter followup period.

In majority of our cases, the treatment involved wound debridement and removal of infection focus, the PMMA, along with systemic antibiotics administered empirically at first, and then based on culture and antibiogram findings. Results were satisfactory in three (cases 1, 2, and 3) of the five cases; however, eliminating the infection and retaining the implants would be the best treatment scenario(Moketal.,2009; Núñez-Pereira etal., 2013) definition of infection, outcomes instrument, use of a control group, and/or sample size. METHODS Thirty-two patients were included. Sixteen patients ("'infection groupl", since removal of the implants may be catastrophic in some cases, resulting in loss of reduction in partially consolidated fractures.

This complication occurred in case 4, which required a new surgical intervention because of loss of reduction and instability of the VFL, with worsening of clinical condition. Thus, surgical removal of PMMA was not considered in case 5; the medical treatment was continued instead. Implant retention, lavage, debridement, and knowledge of the involving microorganism increases the chances of treatment success; sole empirical use of antibiotics has a high risk of failure (Mok et al., 2009).

A study performed by Núñez-Pereira et al. (2013)and who consecutively developed an acute deep surgical site infection. All were appropriately treated by surgical debridement with a tailored antibiotic program based on culture results for 
a minimum of eight weeks. A 'terminal event' or failure of treatment was defined as implant removal or death related to the SSI. The mean follow-up was 26 months ( 1.03 to 50.9 evaluated 43 human patients with surgical site infections after stabilization for spine fusion. They reported that removal of the implants was indicated in the presence of persistent wound discharge and abnormal inflammatory markers (erythrocyte sedimentation rate and C-reactive protein) after multiple debridement, after radiographic evidence of vertebral fusion, or recurrence of infection after treatment, and was done in $23 \%$ of the cases. Surgical replacement of the implants was needed in $44.4 \%$ of these patients where progressive deformity of the vertebral column was noted after removal of the implants, as occurred in case 4 , where the cat had recurrence of the vertebral luxation after removal of the PMMA.

In patients with a high risk of clinical worsening due to removal of the implants, such as case 5 (hemivertebra) of the present study, PMMA with thermostable antibiotics at the site of infection and around the implant may be used. Masuda, Fujibayashi, Otsuki, Kimura and Matsuda (2017), reported the successful treatment of 11 people with refractory infection of the spinal surgical site; they used bone cement with amikacin and vancomycin as $10 \%$ of its total volume, which avoided removal of the implants in 10 patients. The authors state that other than reducing the dead space, this technique also results in antibiotic release at the site for long periods.

Despite the small number of cases reported here, we observe that medium or long term complications may occur in the thoracolumbar spine secondary to the internal use of bone cement, with thinner muscle cover at the implant site compared to the cervical spine; this should be taken into consideration prior to surgery. In veterinary medicine, there are biomechanical studies comparing the efficacy and versatility of alternative methods of vertebral fixation like locking plates and pedicular screws with PMMA in the spine (Early, Mente, Dillard, \&
Roe, 2015; Lewchalermwong, Suwanna, \& Meij, 2018; Sturges et al., 2016), which may have lesser complication rates and be easier to remove and substitute, if necessary.

Based on the data presented in this study, the authors wish to highlight the need for clinical studies that compare the long term efficacy of other methods of vertebral fixation using PMMA and pins or screws, establish expected medium and long term complication rates and need for surgical removal, as well as outline related surgical guidelines.

\section{Conclusion}

The use of bone cement in association with screws or pins is a versatile technique and was effective in stabilizing the vertebral column of the patients in the reported case series. However, late complications can occur, such as open wound and exposure of bone cement to the environment, with or without infections, and in most cases, an additional surgical intervention is needed to remove the focal infection or for implant replacement.

\section{References}

Bruce, C. W., Brisson, B. A., \& Gyselinck, K. (2008). Spinal fracture and luxation in dogs and cats: A retrospective evaluation of 95 cases. Veterinary and Comparative Orthopaedics and Traumatology, 21(3), 280-284.

DiFazio, J., \& Fletcher, D. J. (2013). Updates in the management of the small animal patient with neurologic trauma. Veterinary Clinics of North America: Small Animal Practice, 43(4), 915-940. doi: 10.1016/j. cvsm.2013.03.002

Early, P., Mente, P., Dillard, S., \& Roe, S. (2015). In vitro biomechanical evaluation of internal fixation techniques on the canine lumbosacral junction. PeerJ, 3(8), e1094. doi: 10.7717/peerj.1094

Hettlich, B. (2017). Vertebral fracture and luxation repair. dans A. shores et B. A. brisson (dir.), Current Techniques in Canine and Feline Neurosurgery (1st éd., p. 209-222). Hoboken : Wiley Blackwell. 
Jeffery, N. D. (2010). Vertebral fracture and luxation in small animals. Veterinary Clinics of North America: Small Animal Practice, 40(5), 809-828. doi: 10.1016/j.cvsm.2010.05.004

Lewchalermwong, P., Suwanna, N., \& Meij, B. (2018). Canine vertebral screw and rod fixation system: design and mechanical testing. Veterinary and Comparative Orthopaedics and Traumatology, 31(2), 95-101. doi: 10.3415/VCOT-17-03-0040

Masuda, S., Fujibayashi, S., Otsuki, B., Kimura, H., \& Matsuda, S. (2017). Efficacy of target drug delivery and dead space reduction using antibiotic-loaded bone cement for the treatment of complex spinal infection. Clinical Spine Surgery, 30(9), E1246-E1250. doi: 10.1097/BSD.0000000000000567

Mok, J. M., Guillaume, T. J., Talu, U., Berven, S. H., Deviren, V., Kroeber, M., ... Hu, S. S. (2009). Clinical Outcome of deep wound infection after instrumented posterior spinal fusion. Spine, 34(6), 578-583. doi: 10.1097/BRS.0b013e31819a827c

Núñez-Pereira, S., Pellisé, F., Rodríguez-Pardo, D., Pigrau, C., Bagó, J., Villanueva, C., \& Cáceres, E. (2013). Implant survival after deep infection of an instrumented spinal fusion. The Bone \& Joint Journal, 95-B(8), 1121-1126. doi:10.1302/0301620X.95B8.30784

Petty, W., Spanier, S., Shuster, J. J., \& Silverthorne, C. (1985). The Influence of skeletal on incidence of infection. The Journal of Bone and Joint Surgery, 67(8), 1236-1244.
Ramanathan, S., Vora, T., Gulia, A., Mahajan, A., \& Desai, S. (2017). Pulmonary cement embolism in a child following total elbow replacement for primitive neuroectodermal tumour (PNET) of the humerus. Skeletal Radiology, 46(5), 715-718. doi: 10.1007/ s00256-017-2602-0

Roberts, T. T., Haines, C. M., \& Uhl, R. L. (2017). Allergic or hypersensitivity reactions to orthopaedic implants. Journal of the American Academy of Orthopaedic Surgeons, 25(10), 693-702. doi: 10.5435/ JAAOS-D-16-00007

Shores, A., Braund, K. G., \& Brawner, W. R. Jr. (1990). Management of acute spinal cord trauma. Veterinary Medicine, 85(7), 724-739.

Sturges, B. K., Kapatkin, A. S., Garcia, T. C., Anwer, C., Fukuda, S., Hitchens, P. L., ... Stover, S. M. (2016). Biomechanical Comparison of locking compression plate versus positive profile pins and polymethylmethacrylate for stabilization of the canine lumbar vertebrae. Veterinary Surgery, 45(3), 309-318. doi: 10.1111/vsu.12459

Vallefuoco, R., Manassero, M., Leperlier, D., Scotti, S., Viateau, V.,\& Moissonnier, P. (2014). Surgical repair of thoraco-lumbar vertebral fracture-luxations in eight cats using screws and polymethylmethacrylate fixation. Veterinary and Comparative Orthopaedics and Traumatology, 27(4), 306-312. doi: 10.3415/ VCOT-13-08-0098

Wu, C.-C., Lin, M.-H., Yang, S.-H., Chen, P.-Q., \& Shih, T. T.-F. (2007). Surgical removal of extravasated epidural and neuroforaminal polymethylmethacrylate after percutaneous vertebroplasty in the thoracic spine. European Spine Journal, 16(S3), 32-331. doi: $10.1007 / \mathrm{s} 00586-006-0237-2$ 
